\title{
Processing Plants and Technologies for a Sustainable Mediterranean Food Chain
}

\author{
Francesco Genovese, Giuseppe Altieri, Naouel Admane, Ivan Salamon, \\ and Giovanni Carlo Di Renzo
}

\begin{abstract}
The growing demand of fresh fruit and vegetable, free of pathogens and chemical residues, requires the application of safe and sustainable technologies for extending the storage life of these products. Furthermore, a very interesting and profitable activity is the isolation/extraction of pure natural (herbal) components that could be used by food, pharmaceutical, and cosmetic companies. In this context, several technologies have been developed in order to preserve fruits and vegetables during postharvest, also by using biocontrol agents, natural antimicrobials, GRAS (Generally Recognized As Safe) agents and physical treatments, and to recover valuable compounds as essential oil (from leaf, skin, pulp, or seed) using the most appropriate technology (extraction, distillation, or drying). In this chapter, authors, focusing on some of Mediterranean basin productions that are components of the Mediterranean diet, describe the main sustainable and innovative technologies and the related plants, suitable for management of fruits and vegetables postharvest and for recovery of essential oils from plant materials.
\end{abstract}

\footnotetext{
F. Genovese • G. Altieri • G.C. Di Renzo $(\bowtie)$

Scuola di Scienze Agrarie, Forestali, Alimentari ed Ambientali (SAFE), Università degli Studi della Basilicata (UNIBAS), Via Ateneo Lucano 10, 85100 Potenza (PZ), Italy

e-mail: giovanni.direnzo@unibas.it

N. Admane

Scuola di Scienze Agrarie, Forestali, Alimentari ed Ambientali (SAFE), Università degli Studi della Basilicata (UNIBAS), Via Ateneo Lucano 10, 85100 Potenza (PZ), Italy

CIHEAM - Istituto Agronomico Mediterraneo di Bari (IAMB), Via Ceglie 9, 70010

Valenzano (BA), Italy

I. Salamon

Faculty of Humanities and Natural Sciences, Department of Ecology, University of Presov, 17th November Street, 01, 08116 Presov, Slovak Republic
} 


\section{Introduction}

Since the early time, many species including temperate fruits, vegetables, and herbs have long been cultivated in Mediterranean basin and became elements of the Mediterranean diet.

In the last century, the health benefits were investigated and the interest of the public and scientific communities increased due to both its sensory and nutritional value and the importance in the human diet of specific components as antioxidants, essential oils, vitamins, and phenolics.

Nowadays, it is well known that in order to fulfill the growing demand of fresh but perishable vegetable products, free of pathogens and chemical residues, application of safe and sustainable technologies for extending the storage life of these products is of utmost importance. In addition, a very interesting and profitable growing branch is the isolation/extraction of pure natural (herbal) components that could be used by food, pharmaceutical, and cosmetic companies.

\section{Technologies for the Postharvest Storage of Fruits and Vegetables}

Significant quality improvements of perishable products could be achieved by cooling to the optimal storage temperature immediately after harvest and maintaining this appropriate temperature through the whole handling and transportation chain. Generally, the temperature decrease slows metabolic processes such as respiration and ethylene production, by suppressing ripening related to enzymes, and the development of pathogens. However, most perishable horticultural commodities have an optimal shelf life temperature that differs by commodities, whereas storage below this optimal temperature can induce a rapid tissue deterioration (chilling injury). Furthermore, the relative humidity $(\mathrm{RH})$ can also influence water loss, decay development, the incidence of some physiological disorders, and the maintenance of acceptable visual quality, where an appropriate RH range for storage of fruits is $85-95 \%$ and for most vegetables varies between 90 and $95 \%$.

In the last years, the research about the use of natural biocontrol agents or antimicrobials such as plant extract (essential oil) and salts has been very active. The mechanisms by which microbial antagonists exert their influence on the pathogens have not yet been fully understood. Several modes of action have been suggested to explain the biocontrol activity of microbial antagonist; still, competition for nutrient and space between the pathogen and the antagonist is considered as the major modes of action by which microbial agents control pathogens causing postharvest decay (Ippolito et al. 2000; Ippolito and Nigro 2000; Jijakli et al. 2001).

Essential oils are applied as flavoring agents in foods, and, thanks to their antimicrobial compound content, they have potential as natural food preservation agents. Elizaquivel et al. (2013) proved the efficiency of three essential oils, $1 \%$ 
clove, $2 \%$ oregano, and $0.1 \%$ zataria, at $37{ }^{\circ} \mathrm{C}$ on the infectivity of the Murine norovirus, which has been listed among the five highest-ranking pathogens in terms of the total cost of foodborne illness in the United States.

Salts are inexpensive, easily accepted by consumers, nontoxic, with minor environmental impact at the effective concentrations, and usually used in the food industry. Several inorganic salts show activity against a range of phytopathogenic fungi; in particular, postharvest treatments with calcium chloride and sodium bicarbonate have been proposed as safe and effective alternative means to control postharvest rots of fruit and vegetables. This treatment can be applied alone or in combination with other physical and/or biological treatments (Ippolito et al. 2005; Karabulut et al. 2004).

1-Methylcyclopropene (1-MCP) treatment is an alternative method of slowing ripening which inhibits ethylene action of climacteric fruits. The stable formulation of 1-MCP is a powder in complex with cyclodextrin, which allows to release the product as a gas when the powder comes in contact with water. The highest concentration of 1-MCP approved for use is $1 \mu \mathrm{l} / \mathrm{l}$ (Lurie and Paliyath 2008).

Chlorine dioxide $\left(\mathrm{ClO}_{2}\right)$ is an oxidizing agent with strong antimicrobial proper yeasts and molds, and it is 3.5 times as powerful as chlorine or chlorinated water (Artes et al. 2009; Gomez-Lopez et al. 2009); either gaseous or aqueous form can be used for disinfecting fresh fruits and vegetables (Park et al. 2008). Chlorine dioxide was successfully used to control Escherichia coli on apple skin and strawberries, to wash iceberg lettuce, and it was also able to control Salmonella on red chard leaves and tomato (Keskinen and Annous 2009; Trinetta et al. 2010; Tomas-Callejas et al. 2012).

Ethanol is a common food additive with antimicrobial activity which affects ripening and senescence in some fruit and vegetables. Recently, many studies dealing with table grape preservation techniques have evidenced that the use of ethanol suppressed microbial growth and prevented berry decay; these effects were also found in peaches and citrus fruit (Smilanick et al. 1995).

Electrolyzed oxidizing (EO) water is generated by electrolyzing a $\mathrm{NaCl}$ solution to release free chlorine into the water. The EO water was reported to be effective in reducing E. coli populations on various produce (Pangloli et al. 2009); however, the use of this disinfectant is not sufficient as single treatment, to reduce microbial populations below the desirable safe level, and its effectiveness is also influenced by the presence of organic materials, including fats, carbohydrates, and protein-based materials (Barrera et al. 2012), and by $\mathrm{pH}$, temperature, water hardness, chemical inhibitors, concentration, and contact time (Srey et al. 2013).

Hydrogen peroxide $\left(\mathrm{H}_{2} \mathrm{O}_{2}\right)$ is a strong oxidizer and is effective against a wide range of bacteria, yeasts, molds, viruses, and spore-forming organisms. From the safety point of view, $\mathrm{H}_{2} \mathrm{O}_{2}$ is known to be a safe solution which does not cause allergic reactions, even at concentrations between 0.08 and $0.2 \%$.

Organic acids are recognized as an ideal antimicrobial agent due to their strong oxidizing capacity; they are mostly used as sanitizers of fresh products. The antimicrobial activity of lactic acid, citric acid, acetic acid, and ascorbic acid was 
proved against E. coli and Listeria monocytogenes on iceberg lettuce (Akbas and Olmez 2007), while the malic acid was successfully used to inactivate foodborne pathogens (E. coli, Salmonella typhimurium, and L. monocytogenes) in apple, pear, melon juices, spinach, and lettuce without impairing produce quality (Massilia et al. 2009; Choi et al. 2012).

Ozone $\left(\mathbf{O}_{3}\right)$ is a natural substance in the atmosphere and a potent antimicrobial agent that can be used against a wide spectrum of microorganisms as bacteria, fungi, viruses, protozoa, and bacterial and fungal spores (Srey et al. 2013); it has a strong odor and a powerful oxidant effect on carbon residues dissolved in the washing water as well as on the produce surface. Intermittent ozone treatment (both in air and water) could reduce postharvest losses in orange fruit during longterm storage (Di Renzo et al. 2005), using adequate storage conditions (low temperature and high relative humidity). Authors carried out the trials on Ovale and Valencia oranges (Citrus sinensis Linn Osbeck) inoculated by dipping in a suspension of $P$. digitatum Sacc. and kept at $20^{\circ} \mathrm{C}$ for $24 \mathrm{~h}$ before the treatment. Control was compared with ozonized water $(0.6 \mathrm{mg} / \mathrm{L}$ ozone $)$ and chlorinated water $(50 \mathrm{mg} / \mathrm{L}$ chlorine $)$. After washing, fruits were also stored in an intermittent ozone air mixture ( $0.25 \mathrm{ppm}$ ozone). Decay incidence was assessed as mold incidence caused by blue mold ( $P$. italicum Wehmer) and green mold ( $P$. digitatum Sacc.) or as miscellaneous molds of unidentified fungi. Results showed a synergistic effect of ozone and chlorine treatments in water and of fruit exposure to ozone in air, preventing mycelial growth and sporulation on inoculated fruits. Using ozonized air during cold storage reduced weight loss to about $10 \%$ compared to the control. Ozone could be used in substitution of chlorine to control disease incidence during the long-term storage of oranges. Admane et al. (2014) carried out a study in order to maintain the quality of organic table grapes ("Early Superior Seedless 'Sugraone"') with alternative safe treatments to the sulfur dioxide $\left(\mathrm{SO}_{2}\right)$, not allowed in organic product. Detached grape berries were pretreated by (1) dipping in ethanol and potassium bicarbonate, (2) massive $\mathrm{CO}_{2}$ concentrations, and (3) ozone $\left(\mathrm{O}_{3}\right)$ fumigation, whereas untreated berries were included in the trial as control. Moreover, all the samples were packed in thermo-sealed bags with MAP of $2 \% \mathrm{O}_{2}: 5 \% \mathrm{CO}_{2}: 93 \% \mathrm{~N}_{2}$ and stored at $0{ }^{\circ} \mathrm{C}$ for 45 days. Results showed that after 45 days of storage, weight loss was higher in the sample pretreated with both massive $\mathrm{CO}_{2}\left(70\right.$ and $90 \%$ ) and control. Both the samples pretreated with $\mathrm{CO}_{2}$ at $70 \%$ and $\mathrm{O}_{3}$ at $20 \mathrm{ppm}$ maintained the strength of the berry linked to its pedicel; also the berry and skin firmness were statistically higher in samples pretreated with $\mathrm{CO}_{2}$ at $90-70 \%$ and $\mathrm{O}_{3}$ at $20 \mathrm{ppm}$ in comparison with the control. The skin color parameters and titratable acidity decreased, while $\mathrm{pH}$ increased in all samples in comparison with their initial value. Soluble solid content increased in samples treated with $\mathrm{O}_{3}$ at $20 \mathrm{ppm}, \mathrm{CO}_{2}$ at $70 \%$, and dipping. Sensory evaluation scores gave the decisive data for the selection of the best combination treatments in order to validate their efficiency and that of the film packaging on late-season organic table grape "Scarlotta/Sugraninteen." Samples pretreated by dipping showed the highest scores for crunchiness, firmness, sweetness, and sourness. In conclusion, the efficiency of both film packaging and MAP inhibited the occurrence of berry decay 
in all samples including the control. Furthermore, in recent studies, it was reported also a reduction of fungicides residues in Thompson Seedless table grapes fumigated with $\mathrm{O}_{3}$ (Karaca et al. 2012). $\mathrm{O}_{3}$ is effective at lower concentrations (1-5 ppm) and shorter contact times (1-5 min) than chlorine (Srey et al. 2013), and it can react with organic matter up to 3,000 times faster than chlorine (Rosenblum et al. 2012). However, it may become ineffective with low amounts of organic materials and dirt that could be on the produce external surface.

Coatings consist of a thin layer of edible materials applied to produce surfaces (Campos et al. 2011). The preservation of fresh produce can also be achieved by the application of edible coatings, by decreasing moisture loss and controlled gas $\left(\mathrm{CO}_{2} /\right.$ $\mathrm{O}_{2}$ ) exchange, resulting in reducing respiration rate (Hernandez-Munoz et al. 2008). It was reported that the chitosan has been found to be an ideal preservative coating material for several fresh commodities including strawberries and cherries by limiting fungal decay and slowing down the respiration and ripening process (Han et al. 2004; Dang et al. 2010); furthermore, chitosan coating on minimally processed carrots and fresh-cut broccoli brought a reduction in the mesophilic aerobic bacterial count, without affecting the overall quality of the processed product (Pushkala et al. 2012; Moreira et al. 2011).

\section{Physical Treatments}

Cold Storage Management Refrigerated produce (the primary refrigerated produce are bananas, meat, citrus fruit, fish, and seasonal fruit) are widely stored and transported worldwide, and in the last years, the fruit trade from Mediterranean countries toward extra EU countries (especially Japan, United States, Canada) grew continuously, with increased volume of shipped foodstuff. Produce temperature is the most important factor affecting the quality of fruits and vegetables, which remain alive after harvest. The vegetable tissue metabolic activity requires environmental oxygen and produces carbon dioxide and heat. At any point of the cold chain, produce should be held at its lowest recommended storage temperature, and the rapid cooling after harvest (precooling) is essential to maintain the quality of fresh fruits and vegetables during postharvest handling and distribution (Opara and Zou 2007). In order to optimize the cool chain management and to promote rapid and uniform cooling of produce, several factors are fundamental: (1) the power of the cooling equipments should be adequate to the cooling time required, (2) air circulation around the produce should be adequate to the product type and the packaging material used, (3) accurate control of temperature and RH in the storage room, and (4) the refrigeration plant energy efficiency that dramatically affects the cost of storage. Furthermore, precooling to remove the "field heat" is an effective strategy to reduce the period of high initial respiration rate prior to storage and transportation. Authors (Di Renzo et al. 2011) carried out several empirical studies to optimize the precooling step on various citrus species. A pressure cooling plant, 
Fig. 1 Heat transfer coefficient calculated during the trials for the "control" (room cooling system) and operating the fans at frequency of 35,40 , and $50 \mathrm{~Hz}$. When operating the fan at $50 \mathrm{~Hz}$ frequency, a "h" (heat transfer coefficient) equals to $0.86 \mathrm{Wm}^{-2} \mathrm{~K}^{-1}$ was calculated, five times greater than "h" calculated for the cooling room storage

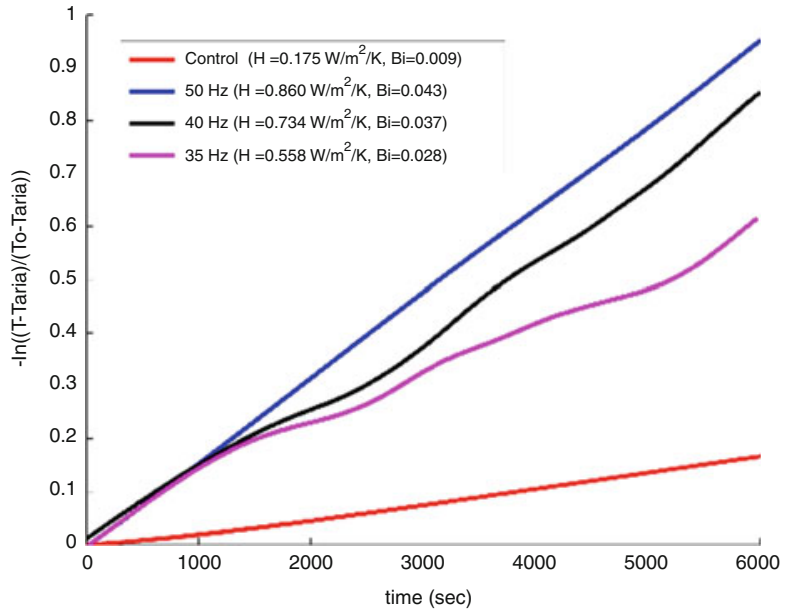

equipped with a temperature control system, was used to study the cooling rate on Tarocco blood oranges.

In the pressure plant, the fan reduces the pressure level to 96-98 $\mathrm{Pa}$ in the space between the pallet rows, and the air velocity around the fruits is generally maintained around $0.8-1 \mathrm{~m} / \mathrm{s}$. Results showed that cooling rate is strictly dependent to both fan speed and pressure level. When operating the fan at $50 \mathrm{~Hz}$ frequency, a " $h$ " (heat transfer coefficient) equal to $0.86 \mathrm{Wm}^{-2} \mathrm{~K}^{-1}$ was calculated, five times greater than " $h$ " calculated for the cooling room storage (Fig. 1).

In a recent research, a tunnel-type forced-air cooler was used to rapidly cool oranges, stacked in pallet, before simulating a container cold transport. For this purpose, a refrigerated container (reefer, $40^{\prime}$ High Cube) was used, available at the Oranfrizer Company (Scordia, Catania, Italy). The refrigeration unit was located on the end wall of the container, defrosting operated automatically every $25 \mathrm{~h}$, and each cycle held for about $30 \mathrm{~min}$. Cold air flows around the fruits in the container through the gratings in the floor and then drawn off again below the container ceiling. The circulating fans force the air through the air cooler, which also acts as the evaporator in the cold circuit, and back through the gratings into the cargo. The container was loaded gradually, starting with the pallet to be placed in the end side of the container, and every time a pallet was loaded on the container and before the final placing, also temperature probes were placed into the fruits, making a little hole (about $0.3 \mathrm{~cm}$ diameter) in the fruits. Data showed a good result in terms of temperature homogeneity, which varied in a short range $\left( \pm 0.5^{\circ} \mathrm{C}\right)$ depending on probe location inside the container; temperature reached a minimum level of about $-0.8^{\circ} \mathrm{C}$ during the early stage when cooling system starts. This minimum level can be considered too low for orange fruits, due to the risk of cold damage rising (about $-1.0{ }^{\circ} \mathrm{C}$ ).

Generally, also a 90-95\% relative humidity $(\mathrm{RH})$ is needed to obtain the best shelf life of most fruits and vegetables, except for few species (bulb onions, garlic, 
winter squashes, ginger). Low RH around the produce causes wilting or shriveling, reducing marketability. When moist air contacts with a cold surface that is at a temperature below the dew point of water vapor in the air, condensation will occur, and frost begins to form if surface temperature is below the freezing temperature of water, so frost growth on heat exchangers placed in the cold room is a common problem for refrigeration systems, and it affects the thermal performance of heat exchangers in several ways (Chen et al. 2003).

Frost growth on heat exchanger surfaces increases the thermal resistance between the fins and the airflow (Na and Webb 2004) and decreases the cooling capacity of heat exchangers used in refrigeration systems and reduces the airflow through heat exchangers and increases the air pressure drop (Chen et al. 2003).

In a recent study (Altieri et al. 2007), authors evaluated the performance of a frosted finned tube heat exchanger for different cooling capacities and heat transfer mechanisms, with the aim to design a new defrosting system based on indirect measure of frost layer present on the heat exchanger surface.

Air temperature, brine temperature, air speed through the cooler fins, and the electric power absorbed by the fans were measured. Data collected during the trials showed that reducing the heat load inside the cold storage room, i.e., increasing the refrigeration power with respect to the same heat load, requires a more frequent defrosting operation and increases energy consumption.

Experimental trials showed that frost deposition is the fastest when the heat transfer mechanism is the free convection. Furthermore, fan power absorption seems to be an optimal marker to control frost on finned tube heat exchanger placed in high-humidity environments. The presence of the frost on the exchanger surface decreased air velocity through the air cooler and caused an increase of fan power absorption around $7 \%$ from the beginning to the end of the test (Fig. 2). The direct correlation between frost thickness and absorbed power makes this parameter suitable to continuous control of defrosting process.

Modified and Controlled Atmosphere Storage A controlled atmosphere (CA) or modified atmosphere (MA) around the produce is created by alterations in the concentrations of the respiratory gases in the storage atmosphere; these alterations
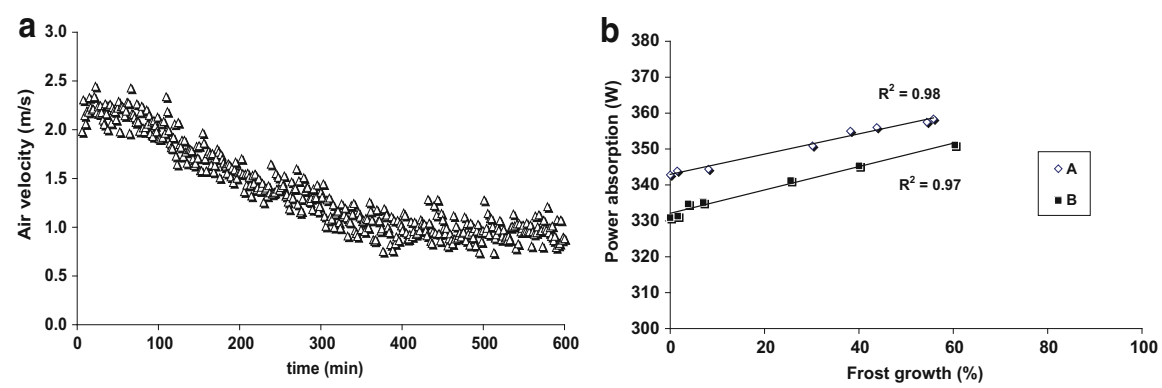

Fig. 2 Frost on the exchanger surface decreased air velocity through the air cooler (a) and caused an increase of fan power absorption (b) around $7 \%$ from the beginning to the end of the test 
include elevation of carbon dioxide $\left(\mathrm{CO}_{2}\right)$ level, reduction of oxygen $\left(\mathrm{O}_{2}\right)$ tension, or both. Whereas the term CA storage generally implies precise control of $\mathrm{O}_{2}$ and $\mathrm{CO}_{2}$ concentrations in the atmosphere, the term MA storage is broader and may indicate any synthetic atmosphere, arising intentionally or unintentionally, in which the composition of its constituent gases cannot be closely controlled. Carbon dioxide is the only gas used inducing a significant level of antimicrobial activity and survival on the produce. These induced environmental conditions have a marked effect on product physiology, starting from altered primary metabolism and respiratory pathways, and involve changes in gene expression, protein accumulation, and metabolite concentrations (Kanellis et al. 2009). During long storage, application of low concentration of $\mathrm{O}_{2}$ is able to delay the decay on cherries, blueberries, raspberries, strawberries, figs, and pomegranates. While storage under CA $\left(12 \% \mathrm{O}_{2}+12 \% \mathrm{CO}_{2}\right)$ for up to 8 weeks controlled significantly postharvest disease and maintained the quality of organic table grapes, storage under $\mathrm{CO}_{2}$ at high concentration ( $90 \%$ or more) is used in order to quickly remove astringency from kaki (or Japanese persimmon), a high nutritional fruit very popular in the Mediterranean area. Di Renzo et al. (2013) carried out a simultaneous $\mathrm{CO}_{2} /$ ethylene gas treatment of persimmon, as opposed to the common sequential application of ethylene following $\mathrm{CO}_{2}$. The influence of both treatments on the fruit quality was evaluated in terms of weight loss, color index, firmness, total soluble solids, tannin content, and juice titratable acidity, immediately after the treatment, after 7 and 21 days, to simulate the shelf life period (fruits were stored at $6{ }^{\circ} \mathrm{C}$ and 85-95\% RH). Results showed the efficacy of the simultaneous $\mathrm{CO}_{2} /$ ethylene treatment that within 7 days after the treatment allows picking up immature persimmons to complete the simultaneous treatment within $24 \mathrm{~h}$ to have ready to eat fruits for market, optimizing the chain of such a short-season produce.

Modified atmosphere packaging is a nontoxic method for keeping quality and extending shelf life of fruits and vegetables (Kader et al. 1989), by reducing respiratory activity, delaying softening and ripening, and reducing the incidence of various physiological disorders and pathogenic infestations (Caleb et al. 2013) due mainly to the relatively low oxygen and high carbon dioxide levels inside the package.

Ultraviolet-C (UV-C) irradiation light is part of the electromagnetic spectrum, with wavelengths between 200 and $280 \mathrm{~nm}$; due to its antimicrobial effect and low cost, this treatment is attractive to the food industry (Shim et al. 2012). The effectiveness of this treatment for microbial inactivation depends mainly on radiation dose and the structure and topography of the surface of the product.

Heat treatment has been recognized as a feasible postharvest treatment for fruits and vegetables with potential to delay ripening and decay, since it is easily applied, leaves no chemical residues, and can reduce the initial population of microorganisms. These effects include changes in tissue respiration, hormone production, particularly ethylene and enzyme activities, and other changes that impact on fruit and vegetable quality. Heat treatments include hot water dips, hot water brushing, and hot air treatments (vapor heat and forced air). The type of high- 
temperature treatment and its duration affects fruit or vegetable ripening or senescence as well as nutritional and quality attributes.

\section{Isolation of Natural Preparations from Plants ${ }^{1}$}

A very interesting and profitable area is the isolation of pure natural substances using plant materials for pharmaceutical, cosmetic, and food companies. The natural products are used as food ingredients, as cosmetics, and as components of pharmaceutical preparations (for example for antitumor, sedative, and UV-protection drugs). Several species are very interesting for the isolation of extracts and manufacture of the preparations for example grape marc, olive pomace, citrus pulp poppy (Papaver somniferum L.), milk thistle (Silybum marianum L.), henna (Lawsonia inermis L.), horse chestnut (Aesculus hippocastanum L.), and leuzea (Rhaponticum carthamoides/Willd./Iljin).

Herbal substances are all mainly whole, fragmented, or cut plants, plant parts in an unprocessed usually dried form but sometimes fresh. Herbal substances are precisely defined by the plant part used and the botanical name according to the binomial system (genus, species, variety, and author). Herbal preparations are obtained by subjecting herbal substances to treatments such as distillation, extraction, and freeze-drying.

Essential oils are odorous products, usually of complex composition, obtained from a botanically defined plant raw material by steam distillation, dry distillation, or a suitable mechanical process without heating. Essential oils are usually separated from the aqueous phase by a physical process that does not significantly affect their composition.

The large-scale technology of essential oil distillation generally consists of a main distillatory apparatus (funnel shaped, thermal isolated), a steam condenser, and an additional apparatus (steam boiler and apparatus for improving of a used water). An inside screw plate is driven by an electric engine, which is installed on the apparatus. This screw plate works as an excellent stirrer. With reference to this system, the container has a mixing apparatus, which is not a usual feature in many other types of commercial equipment. This is extremely useful for a complete distillation procedure in order to obtain high yield of essential oil. The source of steam flow is a boiler (heated by oil, gas, or electricity), and the flow is controlled mechanically, according to the plant mass and cooling requirement. The length of distillation depends on medicinal plant species, which are used to the isolation of essential oils (Salamon 2014; Bucko and Šalamon 2007).

\footnotetext{
${ }^{1}$ Part of the described research about the isolation of components by lyophilization was supported by the Ministry of Education, Science, Research and Sport, Slovak Republic, in the project The Isolation of Plant Natural Components by Lyophilization Process and Modification of their Qualitative-Quantitative Properties (No. 00162-0001 /MŠ SR-3634/2010-11/).
} 
The essential oil is produced by the passage of steam through the plant raw material in a suitable apparatus. The steam is introduced from an external source or generated by boiling water. At last steam and oil vapors are condensed, and the water/essential oil mixture is separated by decantation.

Extracts are preparations of liquid (liquid extracts and tinctures) and solid (dry extracts) consistency, obtained from herbal drugs, which are usually in a dry state.

Liquid extracts (extracta fluida) are liquid preparations in which, generally, one part by mass or volume is equivalent to one part by mass of the dried herbal and animal matter. These preparations are adjusted, if necessary, so they satisfy the requirements in terms of residual solvent content and, where applicable, of constituents. Liquid extracts are prepared by using ethanol in a proper concentration or water to extract the herbal drug or by dissolving a soft or dry extract (which has been produced using the same strength of extraction solvent as is used in preparing the liquid extract by direct extraction) or the herbal drug in either ethanol or water. Liquid extract may be filtered, if necessary. A slight sediment may form on standing, which is acceptable as long as the composition of the liquid extract does not change significantly. Dry extracts are solid preparations obtained by evaporation of the solvent used for their production. Dry extracts usually have a loss on drying or a water content not greater than $5 \% \mathrm{~m} / \mathrm{m}$.

Tinctures (tincturae) are liquid preparations usually obtained using one part of herbal drug or animal matter and ten parts of extraction solvent or one part of herbal drug or animal matter and five parts of extraction solvent. Tinctures are prepared by maceration or percolation using only ethanol for extraction or by dissolving a soft or dry extract of the herbal drug or animal matter in ethanol. Tinctures are usually clear and are filtered, if necessary. A slight sediment may form on standing, which is acceptable as long as the composition of tincture does not change significantly.

Lyophilization (freeze-drying) is carried out using the simple principle of physics called sublimation. This technology is important in pharmaceutical, food, and cosmetic industries (Salamon et al. 2015). The process of freeze-drying consists of freezing at atmospheric pressure and sublimation at reduced pressure. On a larger scale, the process is usually done using a freeze-drying machine. In this step, it is important to cool the material below its triple point (the lowest temperature at which the solid and liquid phases of the material coexist). This ensures that sublimation, rather than melting, will occur in the subsequent step. Due to the fact that larger crystals are easier to freeze-dry, it's fundamental, in order to produce larger crystals, to freeze product slowly (for example cycling temperature up and down).

Primary drying means the sublimation of ice to water vapor and its dissipation from space of lyophilization. Secondary drying is the process of removing residual moisture and is carried out at increased temperatures.

After the freeze-drying process is complete, the vacuum is usually broken with an inert gas, such as nitrogen, before the material is sealed. At the end of the operation, the final residual water content in the product is extremely low, around 1-4\%. The work on optimizing the lyophilization usually consists of two parts: (1) optimization of sample dilution, due to the fact that, after evaporation of 
solvents, extracts from plants become viscous, and (2) optimization of lyophilization program.

Open Access This chapter is distributed under the terms of the Creative Commons Attribution Noncommercial License, which permits any noncommercial use, distribution, and reproduction in any medium, provided the original author(s) and source are credited.

\section{References}

Admane N, Verrastro V, Di Gennaro D et al (2014) Effect of postharvest pretreatments on organic Early Superior Seedless "Sugraone" table grapes assigned to long term storage. In: Abstracts of EGU general assembly, Vienna, 27 April-2 May 2014

Akbas MY, Olmez H (2007) Inactivation of Escherichia coli and Listeria monocytogenes on iceberg lettuce by dip wash treatments with organic acids. J Appl Microbiol 44:619-624

Altieri G, et al (2007) Air-cooler defrosting management and performance optimization in fruit and vegetable cold storage rooms. In: Proceedings of CIGR section VI international symposium on food and agricultural products processing and innovations, Napoli, 24-26 settembre 2007

Artes F, Gomez P, Aguayo E, Escalona V, Artes-Hernandez F (2009) Sustainable sanitation techniques for keeping quality and safety of fresh cut plant commodities. Postharvest Biol Technol 51:287-296

Barrera MJ, Blenkimsop R, Warriner K (2012) The effect of different processing parameters on the efficacy of commercial post-harvest washing of minimally processed spinach and shredded lettuce. Food Control 45:745-751

Bucko D, Šalamon I (2007) The essential oil quality of chamomile, Matricaria recutita L., after its large-scale distillation. Acta Horticult 749:269-274

Caleb OJ, Mahajan PV, Al-Said FAJ, Opara UL (2013) Modified atmosphere packaging technology of fresh and fresh-cut produce and the microbial consequences: a review. Food Bioprocess Technol 6:303-329

Campos CA, Gerschenson LN, Flores SK (2011) Development of edible films and coatings with antimicrobial activity. Food Bioprocess Technol 4:849-875

Chen H, Thomas L, Besant RW (2003) Fan supplied heat exchanger fin performance under frosting conditions. Int J Refrig 26:140-149

Choi MR, Lee SY, Park KH, Chung MS, Ryu SR, Kang DH (2012) Effect of aerosolized malic acid against Listeria monocytogenes, Salmonella typhimurium, and Escherichia coli O157:H7 on spinach and lettuce. Food Control 24:171-176

Dang QF, Yan JQ, Li Y, Cheng XJ, Liu SC, Chen XG (2010) Chitosan acetate as an active coating material and its effect on the storing of Prunus avium L. J Food Sci 75:125-131

Di Renzo GC, Altieri G, D'Erchia L, Lanza G, Strano MC (2005) Effects of gaseous ozone exposure on cold stored orange fruit. Acta Hortic (ISHS) 682:1605-1610

Di Renzo GC, et al (2011) Realizzazione e controllo di un impianto di prerefrigerazione ad aria in depressione per gli agrumi. In: Arti Grafiche Editoriali (ed) Gestione e controllo dei sistemi agrari e forestali, Belgirate, 2011

Di Renzo GC, et al (2013) Preliminary results on the effect of a simultaneous $\mathrm{CO}_{2} /$ ethylene treatment on some quality properties of persimmon fruit. In: Proceedings of the XI international controlled and modified atmosphere research conference (CAMA 2013), Trani, 3-7 giugno 2013

Elizaquivel P, Azizkhani M, Aznar R, Sanchez G (2013) The effect of essential oils on norovirus surrogates. Food Control 32:275-278 
Gomez-Lopez VM, Rajkovic A, Ragaert P, Smigic N, Devlieghere F (2009) Chlorine dioxide for minimally processed produce preservation: a review. Trends Food Sci Technol 20:17-26

Han C, Zhao Y, Leonard SW, Traber MG (2004) Edible coatings to improve storability and enhance nutritional value of fresh and frozen strawberries (Fragaria $\times$ ananassa) and raspberries (Rubus idaeus). Postharvest Biol Technol 33:67-78

Hernandez-Munoz P, Almenar E, Del Valle V, Velez D, Gavara R (2008) Effect of chitosan coating combined with postharvest calcium treatment on strawberry (Fragaria $\times$ ananassa) quality during refrigerated storage. Food Chem 110:428-435

Ippolito A, Nigro F (2000) Impact of preharvest application of biocontrol agents on postharvest diseases of fresh fruits and vegetables. Crop Prot 19:723-725

Ippolito A, El-Ghaouth A, Wilson CL, Wisniewski MA (2000) Control of postharvest decay of apple fruit by Aureobasidium pullulans and induction of defense responses. Postharvest Biol Technol 19:265-272

Ippolito A, Schena L, Pentimone I, Nigro F (2005) Control of postharvest rots of sweet cherries by pre- and postharvest applications of Aureobasidium pullulans in combination with calcium chloride or sodium bicarbonate. Postharvest Biol Technol 36:245-252

Jijakli MH, Grevesse C, Lepoivre P (2001) Modes of action of biocontrol agents of postharvest diseases: challenges and difficulties. Bull OILB/SROP 24(3):317-318

Kader AA, Zagory D, Kerbel EL (1989) Modified atmosphere packaging of fruits and vegetables. Crit Rev Food Sci Nutr 28:1-30

Kanellis A, Tonutti P, Perata P (2009) Biochemical and molecular aspects of modified and controlled atmospheres. In: Yahia EM (ed) Modified and controlled atmospheres for the storage, transportation, and packaging of horticultural commodities. CRC Press, Boca Raton, FL, pp 553-567

Karabulut OA, Gabler FM, Mansour M, Smilanick JL (2004) Postharvest ethanol and hot water treatments of table grapes to control gray mold. Postharvest Biol Technol 34:169-177

Karaca H, Walse SS, Smilanick JL (2012) Effect of continuous $0.3 \mu \mathrm{L} / \mathrm{L}$ gaseous ozone exposure on fungicide residues on table grape berries. Postharvest Biol Technol 64:154-159

Keskinen LABA, Annous BA (2009) Efficacy of chlorine, acidic electrolyzed water and aqueous chlorine dioxide solutions to decontaminate Escherichia coli O157:H7 from lettuce leaves. Int J Food Microbiol 132:134-140

Lurie S, Paliyath G (2008) Enhancing postharvest shelf life and quality in horticultural commodities using 1-MCP technology. In: Paliyath G, Murr DP, Handa AK, Lurie S (eds) Postharvest biology and technology of fruits, vegetables, and flowers - handbook of experimental pharmacology, 1st edn. Wiley-Blackwell, Hoboken, NJ, pp 139-161

Massilia RM, Melgar MJ, Belloso MO (2009) Antimicrobial activity of malic acid against Listeria monocytogenes, Salmonella enteritidis and Escherichia coli O157:H7 in apple, pear and melon juices. Food Control 20:105-112

Moreira MR, Roura SI, Ponce A (2011) Effectiveness of chitosan edible coatings to improve microbiological and sensory quality of fresh cut broccoli. LWT Food Sci Technol 30:1-7

Na B, Webb RL (2004) New model for frost growth rate. Int J Heat Mass Transf 47:925-936

Opara LU, Zou Q (2007) Sensitivity analysis of a CFD modelling system for airflow and heat transfer of fresh food packaging: inlet air flow velocity and inside-package configurations international. J Food Eng. doi:10.2202/1556-3758.1263

Pangloli P, Hung Y-C, Beuchat LR, King CH, Zhao ZH (2009) Reduction of Escherichia coli O157:H7 on produce by use of electrolyzed water under simulated food service operation conditions. J Food Prot 72:1854-1861

Park EJ, Gray PM, Oh SW, Kronenberg J, Kang DH (2008) Efficacy of FIT produce wash and chlorine dioxide on pathogen control in fresh potatoes. J Food Sci 73:278-282

Pushkala R, Parvathy KR, Srividya N (2012) Chitosan powder coating, a novel simple technique for enhancement of shelf life quality of carrot shreds stored in macro perforated LDPE packs. Innov Food Sci Emerg Technol 16:11-20 
Rosenblum J, Ge C, Bohrerova Z, Yousef A, Lee J (2012) Ozonation as a clean technology for fresh produce industry and environment: sanitizer efficiency and wastewater quality. J Appl Microbiol 113:837-845

Salamon I (2014) Aromatic and medicinal herbs of Slovakia. Med Plants 6(3):155-160

Salamon I, Grulova D, Hancianu M, Cioanca O (2015) Optimization of lyophilization technology for purification and stabilization of anthocyanins from elderberry fruits. Acta Hort 1061:245252

Shim W-B, Je G-S, Kim K, Mtenga AB, Lee W-G, Song J-U et al (2012) Effect of irradiation on kinetic behavior of Salmonella typhimurium and Staphylococcus aureus in lettuce and damage of bacterial cell envelope. Radiat Phys Chem 81:566-571

Smilanick JL, Margosan DA, Henson DJ (1995) Evaluation of heated solutions of sulfur dioxide, ethanol, and hydrogen peroxide to control postharvest green mold of lemons. Plant Dis 79:742-747

Srey S, Jahid IK, Ha S-D (2013) Biofilm formation in food industries: a food safety concern. Food Control 31:572-585

Tomas-Callejas A, Lopez-Galvez F, Sbodio A, Artes F, Artes-Hernandez F, Suslow TV (2012) Chlorine dioxide and chlorine effectiveness to prevent Escherichia coli 0157:H7 and Salmonellacross-contamination on fresh-cut Red Chard. Food Control 23:325-332

Trinetta V, Morgan MT, Linton RH (2010) Use of high-concentration-short-time chlorine dioxide gas treatments for the inactivation of Salmonella enterica spp Inoculated onto Roma tomatoes. Food Microbiol 27:1009-1015 